REVISTA DE DERECHO UNED, núm. 5, 2009

\title{
LAS AMBIGÜEDADES DEL RÉGIMEN SEMIPRESIDENCIAL: LA EXPERIENCIA DE LA FEDERACIÓN DE RUSIA
}

\section{THE AMBIGUITY OF SEMI-PRESIDENTIAL SYSTEM: THE CASE OF THE RUSSIAN FEDERATION}

José Antonio PiZarro Marín

Resumen: El semipresidencialismo se ha consolidado en las últimas décadas como un sistema político sugestivo para las nuevas democracias emergentes. La realidad observada en ciertos estados semipresidenciales nos muestra el peculiar hecho de que el modelo tiende hacia la supremacía de la figura del presidente, cuando las mayorías presidencial y parlamentaria coinciden, y hacia un predominio del primer ministro cuando estas mayorías se oponen. Esta tendencia, considerada por muchos autores como un axioma, constituye una cualidad sugerente para los poderes constituyentes.

Sin embargo, estamos observando que por primera vez esta tendencia se invierte en el caso de la Federación de Rusia. Tras las últimas elecciones presidenciales y legislativas, se ha constituido un gobierno de mayoría consolidada - tanto presidencial como parlamentaria - dónde el centro de la actividad política radica en el primer ministro, y no en el presidente de la República. Este artículo analiza las ambigüedades del régimen semipresidencial mediante la observación concreta del sistema político ruso y la evolución experimentada en los últimos años.

Palabras clave: semipresidencialismo, sistema de partidos, liderazgo político. 


\begin{abstract}
Semi-presidentialism has been established as a suggestive political system for the new emergent democracies in the last decades. The situation in certain semi-presidential states shows the peculiar fact that the system has a tendency to supremacy of the presidential figure, when the presidential majority and the parliamentary majority are in agreement, and has a tendency to predominance of the prime minister when these majorities are opposites. This tendency, considered for many authors as an axiom, is a seductive quality for the constituent powers.

However, for the first time, we are noticing that this tendency is being reversed in the case of the Federation of Russia. After the last presidential and parliamentary elections, a government has been constituted with the support of the presidential and parliamentary majorities. Nevertheless, the political activity centre is situated in the prime minister, not in the president of the Republic. The aim of this article is to analyse the ambiguities of semi-presidential regimes through the observation of Russian system evolution in the last years.
\end{abstract}

Key words: semi-presidentialism, party system, political leadership.

Sumario: 1. Introducción.-2. Semipresidencialismo teórico: ausencia de consenso académico.-3. Semipresidencialismo aplicado: la experiencia de la Federación de Rusia.-3.1. Circunstancias históricas constituyentes del semipresidencialismo ruso.-3.2. Los poderes presidenciales: la Constitución de 1993.-3.3. La práctica política rusa y su evolución: el sistema de partidos, las mayorías parlamentarias y el liderazgo con factor cohesionar.-4. Conclusiones.

\title{
1. INTRODUCCIÓN
}

El semipresidencialismo, como sistema de gobierno de los estados democráticos, ha adquirido en los últimos años un papel emergente en el enmarañado debate de la «ingeniería constitucional» ${ }^{1}$. Sin embargo, la práctica política experimentada en las últimas décadas por aquellos países que adoptaron mecanismos institucionales para la generación de un poder ejecutivo de autoridad dual ha derivado en una diversidad de variantes del concepto académico de régimen semipre-

${ }^{1}$ Expresión utilizada por Giovanni Sartori para hacer referencia al proceso constituyente de los países democráticos. SARTORI, G.: Ingeniería constitucional comparada. México, Fondo de Cultura económica, 1994. 
sidencial y de los diferentes modos de clasificar y establecer taxonomías. Esta práctica nos muestra, a su vez, las múltiples realidades sociopolíticas a las que se ha ido adaptando la fórmula semipresidencial.

Desde que, en 1970, Maurice Duverger construyera una primera definición académica de régimen semipresidencial ${ }^{2}$, se ha aceptado ampliamente que este tipo de sistema se caracteriza por instaurar un poder ejecutivo dual. De tal manera que el gobierno quedaría constituido por un presidente, cuyos poderes conferidos son de una importancia mayor que los meramente simbólicos, y por un primer ministro cuya existencia política queda sometida a la confianza del parlamento. Podemos afirmar que en este punto radica la esencia de todo régimen semipresidencial, ya que la doctrina no encuentra aquí divergencias. Sin embargo, la falta de consenso entre los autores comienza a ser patente si nos detenemos en aspectos tales como: la elección presidencial directa o indirecta; los países considerados semipresidenciales; el nivel de competencias atribuidas al presidente; o las distintas formas de clasificar los diferentes tipos de regímenes. Esta variedad de aproximaciones doctrinales nos enseña que el semipresidencialismo adquiere en cierta medida una apreciable ambigüedad de su marco teórico.

Aunque no solamente encontramos esta cualidad en el debate teórico. También podemos catalogar como ambigua a la práctica política semipresidencial. El número de países considerados semipresidenciales puede variar de la lista inicial de cuatro países que Duverger enumeró en 1970 - Austria, Francia, Irlanda y Finlandia-, a un listado que incluya hasta el 22\% de los países democráticos ${ }^{3}$. Las clasificaciones y el establecimiento de taxonomías convergen con la práctica política de este tipo de sistemas, ya que las distintas tipologías se elaboran tras la observación directa del grupo de países considerados semipresidenciales.

Derivado del concepto duvergeriano, se estableció originariamente una clasificación dicotómica entre semipresidencialismos de presidencia fuerte y semipresidencialismo de presidencia débil o simbólica. Concretamente en esta línea, Rafael Martínez elabora una clasificación que diferencia entre estados «aparentemente semipresidencialistas» $\mathrm{y}$ «realmente semipresidencialistas ${ }^{4}$, dónde los pri-

2 DUVERGER, M.: Instituciones politicas y derecho constitucional. Paris PUF, 1970.

${ }^{3}$ LEHOUCQ, F.: ¿Es el semipresidencialismo una opción viable?. Revista Política y Gobierno [México], volumen XIV, n. ${ }^{\circ}$ 2, II semestre 2007, p. 513.

4 MARTÍNEZ, R.: El semipresidencialismo: estudio comparado. Universitat de Barcelona, 1998. 
meros se caracterizan por un comportamiento tendente al parlamentarismo y los segundos al presidencialismo. Cierta similitud es observable con la tipología de Shugart y Carey que distinguen entre sistemas «premier-presidentialism» en el cual un primer ministro con primacía convive con un presidente con fuertes poderes presidenciales, y sistemas "president-parlamentary» dónde es el presidente el centro de la actividad política y su gabinete queda sometido a la confianza del parlamento ${ }^{5}$.

A pesar de la variedad del espectro clasificatorio, podemos encontrar un marco común que se deduce de las distintas aproximaciones. El semipresidencialismo tiende hacia un predominio de la figura del presidente cuando las mayorías presidencial y parlamentaria coinciden. Y hacia un predominio de la figura primer-ministerial cuando estas mayorías se oponen. Pero, ¿puede un régimen semipresidencial evolucionar de una tendencia inicial a otra? ¿Puede evolucionar de una tipología a otra distinta? Si consideramos que sí es posible, un estado determinado podría optar por constituirse en un sistema semipresidencial mediante uno de los dos subtipos, o mediante alguna forma mixta, y evolucionar hacia un tipo de semipresidencialismo distinto como consecuencia de la práctica política ejercida. La ambigüedad del sistema semipresidencial también reside en su capacidad de adaptarse a diferentes prácticas políticas, en diferentes momentos políticos.

Este es el caso de la Federación de Rusia. Si partimos de la clasificación de Shugart y Carey observamos que el liderazgo ejercido por el presidente Vladimir Putin consolidó, durante una primera fase, un sistema "president-parlamentary», que ha comenzado recientemente a evolucionar, en una segunda fase, hacia un sistema «premier-presidentialism». Tras la finalización del mandato presidencial de Putin y su posterior toma de posesión como primer ministro, la práctica política evidencia que el papel central de la actividad política sigue girando entorno al liderazgo de Putin. Y que este ejerce un protagonismo similar - al menos - al liderazgo desarrollado por el nuevo presidente de la República, Dimitri Medvedev.

En este aspecto, la experiencia política rusa podría suponer una importante novedad en la historia del semipresidencialismo. Hasta ahora, en aquellos países semipresidenciales dónde se ha producido la convergencia entre una mayoría presidencial y una mayoría par-

5 SHUGART, M. S. y CAREY, J. M.: «Presidents and Assemblies». Cambridge University Press 1992. 
lamentaria de la misma afinidad política, se ha traducido en un predominio de la actividad presidencial sobre la del primer ministro. Ante un posible choque de egos, el liderazgo presidencial prevalece sobre el liderazgo de cualquier otro miembro del gobierno. Tómese como ejemplo el paradigma francés. Sin embargo, si observamos la experiencia rusa, el predominio del primer ministro no se está materializando como consecuencia de una cohabitación - por causa de un gobierno de mayoría divida-, sino por el papel hegemónico que éste ha conservado tras su elección como primer ministro en 2007.

¿Está girando Rusia hacia un nuevo modelo pragmático de semipresidencialismo? ¿Se está invirtiendo el principio del predominio presidencial para las situaciones de mayorías consolidadas? El objetivo de este artículo consiste en comprobar en qué medida existe tal predominio de la actividad política del primer ministro Vladimir $\mathrm{Pu}$ tin sobre la actividad del presidente Dimitri Medvedev, así como analizar e identificar cuáles son las variables de este predominio. Para ello, observaremos la habilidad que adquieren los regímenes semipresidenciales de evolucionar de una tipología a otra, como consecuencia de su cualidad de ambiguo.

Dada la novedad rusa, sería conveniente la búsqueda de un nuevo enfoque que identifique la teoría y la práctica semipresidencial con la experiencia vivida en el sistema político ruso en los últimos años. Este artículo se estructura con un primer apartado dedicado a analizar los distintos enfoques establecidos sobre el concepto académico y sobre las tipologías del régimen semipresidencial. Nos centraremos en hallar la aproximación conceptual y clasificatoria más adecuada para el sistema ruso. En un segundo apartado, titulado «semipresidencialismo aplicado», nos centraremos en la evolución histórica del sistema semipresidencial a través de las tres oleadas democratizadoras. Y, finalmente, nos detendremos en identificar y analizar las variables que caracterizan al sistema ruso actual: la variable histórica constituyente, las competencias presidenciales, la iniciativa legislativa, el sistema de partidos y el liderazgo.

\section{SEMIPRESIDENCIALISMO TEÓRICO: AUSENCIA DE CONSENSO ACADÉMICO}

El semipresidencialismo como doctrina se caracteriza por tener una vida relativamente reciente en comparación con el parlamentarismo. Han transcurrido casi cuatro décadas desde que se cimentara una primera definición académica. Este breve recorrido histórico 
puede ofrecernos una explicación de por qué esta doctrina posee un marco teórico calificable de ambiguo.

La importancia que la fórmula semipresidencial ha ido adquiriendo en el diseño de las nuevas constituciones democráticas, se ha traducido en un incremento de nuevos enfoques y aproximaciones al debate académico. Como bien afirma el profesor Andrés Malamud, "la heterogeneidad del semipresidencialismo es tan amplia que la utilidad del concepto resulta cada vez más comprometida» ${ }^{6}$.

Esta imprecisión teórica no puede sino dilatarse aún más con la aportación al debate académico de la experiencia rusa. Sería conveniente dilucidar un nuevo enfoque de semipresidencialismo que albergue la posibilidad de un predominio de la figura del primer ministro sobre la presidencial, no para casos de cohabitación, sino para casos de gobiernos con mayorías consolidadas. Así como, sería conveniente la búsqueda de un enfoque unitario que articule las distintas aproximaciones teóricas con las múltiples posibilidades pragmáticas que se pueden desarrollar en la práctica semipresidencial.

Los distintos enfoques conceptuales, que los autores han ido aportando en las últimas décadas, han configurado un marco teórico disonante. Las divergencias también son notables en otros aspectos como el establecimiento de clasificaciones y taxonomías, en el número de países catalogados como semipresidenciales, en las variables tomadas para el análisis de un caso concreto, así como en los argumentos en pro y en contra sobre la adopción de este tipo de sistemas.

El antecedente de esta disonancia tiene su origen en Francia. Ocho años después de la aprobación por referéndum de la propuesta gaullista sobre la elección popular de la presidencia de Francia, el profesor Maurice Duverger desarrolló una primera definición académica de «régimen semipresidencial». Desde entonces, las distintas ideas sobre la naturaleza del régimen semipresidencial y sobre qué terminología empleada es la más adecuada, han protagonizado uno de los ejes principales del debate. Esta importancia radica en que el hecho de definir al semipresidencialismo como un sistema híbrido, o como un sistema puro, influirá en la adopción de una terminología determinada o de otra distinta.

Como pionero, Duverger decidió identificar un nuevo sistema que no armonizaba con los cánones de los otros dos modelos clá-

6 MALAMUD, A.: Semipresidencialismo a la portuguesa. Crisis del modelo 2004 en la cuna de la tercera ola. Boletín de la Asociación Latinoamericana de Ciencia Política, año 2004. 
$\operatorname{sicos}^{7}$. Definió al «ejecutivo dual» como «una organización gubernamental dónde se encuentran frente a frente un Jefe de Estado y un Gabinete ministerial bajo la presidencia de uno de los ministros, en calidad de jefe del Gobierno». Duverger arguyó que mientras en el parlamentarismo el dualismo es aparente - debido a la posición simbólica de su jefe de Estado-, en el semipresidencialismo ese dualismo es efectivo debido a que las competencias presidenciales "son mayores que las de un Jefe de Estado parlamentario». Una vez determinada la naturaleza de ese sistema de gobierno que había observado tras el referéndum francés de 1962, Duverger optó por denominar a este nuevo sistema con el término "semipresidencial». El motivo de esta decisión se fundamentó en la consideración de que el elemento esencial del sistema residía en la elección del presidente por sufragio universal, a pesar de sus similitudes con el parlamentarismo. El jefe de Estado se convertiría - junto con el parlamento- en representante directo de la soberanía popular. La existencia de dos fuentes de legitimidad soberana significaría para Duverger la cercanía de este sistema al presidencialismo.

Dada la definición, el profesor Duverger identificó —en un primer momento- a Francia (desde 1962), Austria, Finlandia y la Alemania de Weimar como países semipresidenciales. Años más tarde, ampliaría la lista a Irlanda, Islandia y Portugal tras la introducción de un matiz que distinguiría entre países «aparentemente semipresidenciales» y países «de práctica semipresidencial» ${ }^{8}$. Incluyendo en el primer grupo a países donde el presidente - como en el caso de Irlanda - es elegido popularmente pero éste apenas ejercita competencias sustanciales. He aquí el inicio de la ambigüedad del marco teórico semipresidencial.

La teoría duvergeriana plasmó el núcleo de la controversia doctrinal en dos aspectos: la consideración del semipresidencialismo como un sistema híbrido y la definición de los elementos inherentes de todo régimen semipresidencial en la elección directa o no del presidente por sufragio universal, y en la sustancialidad de los poderes presidenciales. Duverger identificó a la elección presidencial por sufragio universal como el principio fundamental de todo sistema semipresidencial, descuidando - a nuestro parecer- otros aspectos relacionados con la práctica política de un país.

7 DUVERGER, M.: Instituciones Políticas y Derecho Constitucional. Ediciones Ariel, Barcelona 1970; pp. 178-219.

8 DUVERGER, M.: «Le concept de regíme semi-présidentiel», en «Les Regímenes Semi-Présidentiels», bajo la dirección de Maurice Duverger. Presses Universitaires de France, 1986. 
Esta formulación teórica trajo consigo una retahíla de matices introducidos por otros autores. De entre los más importantes puede destacarse la reformulación planteada por Robert Elgie en 1999. Elgie resalta la necesidad de buscar un planteamiento objetivo para evitar que la inclusión o exclusión de los países considerados semipresidenciales se dirima bajo un criterio final subjetivo. De esta forma, define al semipresidencialismo como aquel «régimen donde un presidente elegido por un mandato fijo convive junto con un primer ministro y un gobierno quienes son responsables ante el parlamento ${ }^{9}$. Por un lado, con esta acepción minimalista, se prescinde de las dos condiciones esenciales de la definición duvergeriana: que la elección presidencial sea directa y que los poderes presidenciales sean considerables. Por otro lado, Elgie consigue identificar de una forma más diáfana los países semipresidenciales. En este sentido, son considerados semipresidenciales países que, como Finlandia (hasta 1997), poseen presidentes no elegidos por sufragio directo pero con importantes poderes ejecutivos. Y también serían considerados como tales, aquellos países que, como Irlanda, poseen presidentes elegidos por sufragio directo cuyas competencias son simbólicas.

Según nuestro parecer, la definición de Elgie no acaba con esa necesidad de recurrir a un criterio subjetivo para dirimir qué países son considerados semipresidenciales. En su concepto podemos hallar una imprecisión significativa al abrirse la posibilidad de considerar semipresidenciales a aquellas repúblicas parlamentarias que eligen a sus presidentes "por un mandato fijo». Creemos que la definición de Elgie es adecuada pero no acaba con la arbitrariedad en la designación de qué países componen la lista ${ }^{10}$.

Sin embargo, una definición académica más rigurosa de sistemas parlamentarios «semipresidencializados» podría solventar, en alguna medida, la imprecisión del concepto elgieniano. Esta fue la solución empleada por el Tribunal Constitucional de Lituania que, en 1998, definió en una sentencia a su régimen constitucional como

9 ELGIE, R.: «The politics of semi-presidentialism», en Semi-presidentialism in Europe. Oxford University Press, 1999; pp. 12-13.

${ }_{10}$ Otra interpretación del concepto de Elgie puede llegar a concluir que el autor no prescinde ni de la elección presidencial directa ni de la concesión de poderes notables, sino que los obvia. De todos modos, la descripción no expresa de ambos matices, conduce a la indefinición del concepto en sí. 
«un régimen parlamentario con ciertas particularidades de una forma semipresidencial mixta ${ }^{11}$.

De cualquier manera, la elección directa y la sustancialidad de las competencias presidenciales constituyen los motores del dilema teórico. Algunos autores arguyen que la elección por sufragio universal del presidente no es un elemento existencial del semipresidencialismo. En este sentido, podemos encontrar el polo opuesto del concepto duvergeriano en argumentos de autores como O'Neill. En su enfoque, define al régimen semipresidencial como "aquel en el cual el poder ejecutivo queda dividido por un primer ministro como cabeza del gobierno y un presidente como jefe de estado, y donde poderes sustanciales residen en el presidente» ${ }^{12}$. Con una formulación similar a la de Elgie, este autor considera que el requisito existencial del sistema se circunscribe a la efectividad ejecutiva de los poderes presidenciales, soslayando la importancia de la elección popular directa. El problema subyace aquí en la identificación de cuales son las competencias presidenciales consideradas sustanciales, y cuales simbólicas. El método utilizado para esta identificación también podría incurrir en el empleo de un criterio de ámbito subjetivo. Y a su vez, ese criterio subjetivo, podría incurrir en un grado aún mayor de ambigüedad a la hora de enumerar los países semipresidenciales.

De cualquier forma, existe un cierto consenso en la identificación de competencias presidenciales aceptadas como sustanciales. A saber: el nombramiento del primer ministro, su destitución, la disolución del parlamento, la iniciativa legislativa, el veto legislativo, el derecho a la convocatoria de referéndum, la interposición del recurso de constitucionalidad, la potestad reglamentaria, el nombramiento de funcionarios, el nombramiento de miembros del Tribunal Constitucional, y las competencias en política exterior y defensa. Estas competencias quedan vinculadas a la voluntad política del presidente y están alejadas de la esfera de lo simbólico. Desde nuestro punto de vista, la configuración del papel del presidente en la vida política no viene determinado únicamente por las potestades que le han sido conferidas, sino por la combinación de éstas con la práctica política aplicada en el país.

11 Sentencia del Tribunal Constitucional de Lituania del 10-1-1998. Comentada en: MATSUZATO, K.: An Eternally Unfinished Parliamentary Regime? Semipresidentialism as a Prims to View Lithuanian Politics, en «Acta Slavica Iaponica», Tomo 23, pp. 146-170.

12 Definición de O’Neill descrita por Robert Elgie en su artículo «The politics of semi-presidentialism», en Semi-presidentialism in Europe, Oxford University Press, 1999; p. 4. 
El concepto duvergeriano causa discrepancias no sólo en determinación de los elementos esenciales de semipresidencialismo, sino además, en la denominación en sí del término. La idoneidad de utilizar el término «semipresidencial» para denominar a este tipo de régimen, es motivo de controversia. Se suele relacionar el origen del término «semipresidencial» en un contexto mediático. En concreto, se atribuye el origen del término al periodista francés Hubert BeuveMéry, director de Le Monde en $1959^{13}$. Pero fue Duverger quien enunció la naturaleza híbrida del régimen semipresidencial en su definición de 1970. Años más tarde, en 1996, insistió en el carácter mixto de este régimen en un artículo en el que diferenciaba los sistemas «semiparlamentarios» de los sistemas semipresidenciales. En él, afirmaba literalmente que «los dos regímenes [semiparlamentario y semipresidencial] son a la vez, parlamentarios, porque el Gobierno es responsable ante las cámaras, a las que puede disolver, y presidenciales, porque el pueblo elige a la autoridad ejecutiva» ${ }^{14}$.

Siguiendo este enfoque, los profesores Antonio Garrido y Rafael Martínez desarrollan la idea de la hibridez bajo un criterio que unifique las diversas tipologías de sistemas de gobiernos mediante - lo que ellos llaman - un «continium». En un mismo eje se ubicarían los distintos modelos de tal forma que en un extremo se situarían los sistemas de gobiernos presidenciales puros, y en el otro extremo, los sistemas parlamentarios puros. El resto de los sistemas que no compartan los cánones de los modelos puros, serían considerados "sistemas mixtos de tendencia presidencial o de tendencia parlamentaria $»^{15}$.

Frente a esta tesis, se alinean aquellos que defienden la idea de que el sistema semipresidencial constituye por sí mismo un sistema puro. Robert Elgie cree que no hay motivo para considerar que el régimen semipresidencial sea una mezcla de otros sistemas. El prefijo «semi», en este contexto, no tiene por qué ser sinónimo de «mitad». Por lo que el sistema semipresidencial constituye en sí mismo un régimen tan puro como lo son los otros clásicos ${ }^{16}$. Petra Schleiter ar-

13 Robert Elgie puntualiza que el propio Duverger reconoció que fue Beuve-Méry el primero en usar el término. ELGIE, R.: «The Politics of Semi-Presidentialism» en Semi-Presidentialism in Europe, dirigido por Robert Elgie. Oxford University Press 1990, p. 2.

${ }_{14}$ DUVERGER, M.: Los nuevos regímenes parlamentarios. Diario El País, 29-05-96.

15 MARTÍNEZ, R. y GARRIDO, A.: Sistemas Mixtos de Tendencia Presidencial. Institut de Ciencies Politiques y Socials, Barcelona 2000.

${ }^{16}$ ELGIE, R.: "The politics of semi-presidentialism», en Semi-presidentialism in Europe, Robert Elgie, Oxford University Press, 1999; p. 8. 
guye que el semipresidencial es un sistema único debido a que también es único el hecho de que el origen del gobierno sea el resultado de una negociación entre las dos instituciones popularmente electas: presidente y parlamento ${ }^{17}$.

Más contundentes son Matthew S. Shugart y John M. Carey que parten de la base de considerar el término «semipresidencial» como un error. Dicho término les supone que tal régimen se situaría a mitad de camino entre presidencialismo y parlamentarismo, cuando por el contrario, el sistema ha exhibido características diferenciales propias $^{18}$. En su lugar, y dejando a un lado los regímenes parlamentarios, los autores centran su atención en los sistemas cuyos presidentes son elegidos popularmente, y proponen la definición de tres clases esenciales. En primer lugar, encontramos al presidencialismo, como aquel régimen basado en la máxima separación de poderes posible, y dónde el gobierno se forma tras la elección de su presidente por votación popular directa. En segundo lugar, Shugart y Carey definen con el término "premier-presidentialism» como el tipo de sistema en el que el presidente electo adquiere poderes significativos, aunque el gabinete, con un primer ministro a la cabeza, sólo depende de la confianza del parlamento en cuánto a su nombramiento como a su destitución. En un tercer lugar, los autores definen con el término «president-parlamentary» como el tipo de sistema en el que un presidente electo popularmente adquiere la competencia de nombrar y destituir al primer ministro, así como también posee iniciativa legislativa. Además, en este tipo de sistema, el primer ministro y su gabinete están sometidos a la confianza del parlamento, lo que significa que existe una competencia compartida entre presidente y la Asamblea en cuanto a la destitución del premier ${ }^{19}$. Ambos términos, "premier-presidentialism» $\mathrm{y}$ "president-parlamentary», son formas originales de llamar al régimen semipresidencial con nombres alternativos.

Dada la ambigüedad y la imprecisión del marco teórico del régimen semipresidencial, cualquiera de los enfoques planteados podría adaptarse a la experiencia del régimen ruso y establecer un análisis aproximativo de su evolución. Sin embargo, preferimos recurrir al en-

17 SCHLEITER, P.: «Semipresidencialismo: decisiones constitucionales y consecuencias jurídicas», en Revista Política y Gobierno [México], volumen XIV, n. ${ }^{\circ}$ 2, II semestre 2007; pp. 523.

18 SHUGART, M. S. y CAREY, J. M.: Presidents and Assemblies. Cambridge U. Press 1992; pp. 23.

19 También conocido como sistema de doble confianza, por la existencia de un procedimiento presidencial y un procedimiento parlamentario para destituir al primer ministro. 
foque de Shugart y Carey, y la dicotomía entre sistemas premier-presidentialism y president-parlamentary, para trazar una análisis sobres las novedades aportadas por el gobierno semipresidencial ruso.

\section{SEMIPRESIDENCIALISMO APLICADO: LA EXPERIENCIA DE LA FEDERACIÓN DE RUSIA}

El régimen semipresidencial no solamente muestra ambigüedades e imprecisiones en su marco teórico. También se muestran en su práctica política. Los poderes constituyentes adquieren un amplio margen para elegir entre la institucionalización de una presidencia de poderes simbólicos o una de poderes sustanciales. Este margen de elección determinará el tipo de praxis que se desarrollará a priori en un régimen determinado. Sin embargo, la elección inicial del proceso constituyente puede variar durante la evolución política de un país en función de la práctica que se ejerza en cada momento. De esta forma, un régimen que sitúa la figura presidencial como el centro de gravedad de la actividad política, puede girar hacia un sistema dónde es el primer ministro quien ejerce el rol más importante en la actividad del gobierno. Esta puede ser la situación en casos cohabitacionales, como ocurre en el régimen francés. $\mathrm{O}$ incluso también puede ser la situación en casos no cohabitacionales, dónde presidente y primer ministro pertenecen a la misma mayoría política, cómo recientemente ha sugerido el régimen ruso.

La institucionalización del semipresidencialismo como régimen constitucional se ha materializado progresivamente de forma paralela a las tres oleadas democratizadoras que Samuel Huntington desarrolló en su tesis sobre la evolución histórica de las democracias liberales $^{20}$. De esta forma, podemos diferenciar tres oleadas o etapas (ver cuadro 1). Una primera oleada quedaría constituida por el periodo de entreguerras (1919-1939), dónde se instituyeron las primeras constituciones semipresidenciales como Weimar o Finlandia. Precedida de una contraoleada caracterizada por el auge de totalitarismos, surgiría una segunda oleada, entre 1943 y 1962, dónde se consolidaron regímenes semipresidenciales como la Quinta República francesa. Y finalmente, una tercera oleada que se iniciaría en 1973 (y que seguiría vigente a día de hoy), dónde el semipresidencialismo alcanzaría su máximo apogeo tanto en el plano académico como en su

${ }^{20}$ HUNTINGTON, S.: La Tercera ola: la democratización de finales del siglo XX. Piados, 1998. 
puesta en práctica. Una amplia gama de países adoptaría este modelo: desde Portugal en 1974, hasta los nuevos regímenes constitucionales emergentes tras el colapso de la Unión Soviética. Fue por tanto, en el marco de histórico de esta tercera oleada semipresidencial, cuando Rusia optó en 1993 por configurar un régimen constitucional.

\subsection{Circunstancias históricas constituyentes del régimen semipresidencial ruso}

La tercera oleada consagró al semipresidencialismo como una importante alternativa en los países en vías de democratización. En los años noventa, tras el colapso de la Unión soviética, diecisiete países del bloque comunista adoptaron constituciones semipresidenciales ${ }^{21}$. A diferencia de Francia, estos países adoptaron el modelo semipresidencial tras una experiencia totalitaria. Y muchos de ellos, no habían conseguido asentar en su pasado un sólido Estado de derecho.

El semipresidencialismo se implanta —en estos países- con la idea de optimizar al máximo la democratización de las instituciones, mediante el sometimiento por sufragio universal tanto del poder ejecutivo, así como del poder legislativo. Aquellos antiguos países autoritarios que se inclinaron por constituirse bajo un semipresidencialismo de actividad presidencial simbólica (premier-presidentialism) -Bulgaria o Eslovenia-, se caracterizaron por poseer un proceso constituyente orquestado por la institución parlamentaria y orientado hacia la búsqueda del consenso entre los distintos sectores sociales y políticos. Sin embargo, la situación fue distinta en aquellos otros países ex-comunistas que optaron por constituirse bajo un semipresidencialismo de fuerte actividad del presidente (president-parlamentary). En estos casos, el proceso constituyente fue orquestado por la institución presidencial prevaleciendo sus intereses ante la institución parlamentaria. Rusia optó por esta vía tras la disolución de la URSS.

En Rusia, el semipresidencialismo se materializó como resultado de un proceso constituyente en el que predominó la desconfianza mutua de las instituciones. Esta suspicacia ha sido una constante his-

21 Armenia, Azerbaiyán, Bielorrusia, Bosnia, Georgia, Uzbekistán, Kirguistán, Rumania, Serbia, Tayikistán, Ucrania, Polonia, Bulgaria, Croacia, Lituania, Eslovenia y Macedonia. De los cuales, algunos, como Georgia, han adoptado modelos de fuerte actividad presidencial, y otros, como Croacia, han optado por una presidencia de carácter simbólica. 
tórica en este país. La desconfianza del pueblo hacia las instituciones y de las instituciones entre sí es fruto de un largo proceso histórico. El recelo popular, el desencanto con la clase política y la resignación, que se forjaron en el zarismo y se perpetuaron con el estado soviético, siguen latente hoy en la memoria colectiva.

Este sentimiento estuvo presente en el proceso constituyente y tuvo una influencia notable en la elaboración del texto constitucional de 1993. El temor hacia una constitución que configurase un presidente con fuertes poderes que supusiera un cierto continuismo histórico de un ejecutivo autoritario, llevó al parlamento ruso a presentar un modelo alternativo y a entrar en litigio con el gobierno. Tras la disolución de la URSS en 1991, dos modelos se opusieron en el debate constitucional. Frente a la propuesta de limitación de los poderes presidenciales y su sometimiento al control parlamentario presentada por el Parlamento ruso - Congreso de los Diputados del Pueblo y del Soviet Supremo de Rusia-, se encontraba la propuesta presidencialista elaborada por el gabinete de Boris Yeltsin. Sin embargo, la canalización de la soberanía popular en el proceso constituyente quedaba legitimada en la figura de Yeltsin, quien en 1991 fue elegido presidente de Rusia por sufragio universal. Mientras que la legitimidad democrática de ambas cámaras quedaba mermada por la ausencia de unas elecciones parlamentarias completamente libres ${ }^{22}$. A pesar de esta ventaja en legitimidad popular, Yeltsin optó por resolver el litigio disolviendo el Parlamento ruso mediante el uso de la fuerza, imponiendo ulteriormente un texto constitucional definitivo que instauraba un régimen semipresidencial que favorecía sus ambiciones presidenciales.

En el nuevo régimen democrático, algunos elementos del anterior régimen permanecieron latentes, ya que el tránsito de la dictadura a la democracia fue orquestado - aunque con fuertes divergencias internas- por la elite soviética. La transición política no supuso una ruptura pactada, sino más bien, una reforma consensuada por las elites políticas. Sin embargo, la elección del sistema semipresidencial como modelo de gobierno fue más bien fruto del oportunismo que del consenso. Cuando Boris Yeltsin decidió someter a sufragio universal la presidencia rusa, lanzando un órdago a la antigua nomenclatura soviética, comenzó a gestarse las bases del semipresidencialismo.

${ }^{22}$ El Partido Comunista seguía designando en 1993 a los candidatos que se presentarían a las elecciones del Soviet Supremo de Rusia. 
Hasta entonces, la Constitución soviética de 1918, así como en sus sucesivas reformas (1936, 1964, 1977 y 1985), establecía —al menos en el plano teórico- una estructura institucional semejante al parlamentarismo. Considerando las diferencias evidentes entre el modelo democrático planteado en la Constitución y la práctica totalitaria ejercida, el Soviet Supremo (Verhovni Soviet), órgano «depositario del poder político» (artículo 30), era el encargado de elegir al «Presidium» como institución que dirigía la actividad política del gobierno. Con la disolución de la Unión Soviética el 25 de diciembre de 1991, y la dimisión de Gorbachov, se configuró de facto un sistema semipresidencial, o por lo menos presidencial, ya que en 1992 convivían en Rusia un presidente elegido por sufragio universal, y un parlamento heredero del sovietismo.

A diferencia de las constituciones búlgara o eslovena, la instauración de un sistema semipresidencial que limitase los poderes presidenciales, no fue un objetivo conseguido por el Parlamento ruso. Más bien se produjo el efecto adverso. Una vez resuelto el conflicto entre el presidente y el parlamento mediante el recurso a la autoridad militar, la constitución semipresidencial sirvió para establecer un sistema de fuertes poderes en favor del jefe de Estado, con un sistema de pesos y contrapesos que favorecería a la institución ejecutiva. La instauración de un modelo de presidencia fuerte bajo una fórmula semipresidencial supuso una continuación por otros medios de un poder ejecutivo de tendencia autoritaria en Rusia. Vemos por tanto que el semipresidencialismo tiene una alta capacidad de adaptación a distintas realidades políticas. Cualidad que deriva de su grado de ambigüedad.

\subsection{Los poderes presidenciales: la Constitución de 1993}

El semipresidencialismo concede al constituyente un amplio margen para delimitar el número de prerrogativas presidenciales y el grado de importancia de cada una de ellas. El constituyente puede, por tanto, optar por instituir un régimen con una trascendente actividad presidencial en la actividad política (president-parlamentary) o un régimen con una presidencia simbólica (premier-presidentialism).

Para medir el grado de profundidad de las competencias otorgadas al presidente de la Federación de Rusia, tendríamos que recurrir al Capítulo Cuarto de la Constitución de 1993. Entre sus competencias habría que delimitar cuáles pertenecerían al ámbito de lo simbólico y cuáles al ámbito ejecutivo. La potestad ejecutiva del presi- 
dente queda visiblemente establecida en el artículo 80.3 al conferirle «las líneas básicas de la política doméstica y exterior». Sin embargo, la aplicación del programa político le correspondería en la práctica al primer ministro, que aunque es nombrado por él, debe someterse a la investidura de la Duma.

La posibilidad de la disolución parlamentaria del jefe de Estado (artículo 111) inclina el sistema de checks and balances - pesos y contrapesos - en favor de la presidencia, sin que exista posibilidad de destitución del presidente por parte de la Duma, a excepción de la exigencia de responsabilidad penal (Impeachment). Sin embargo, la necesaria convergencia de las voluntades de ambas instituciones en el nombramiento del gobierno, confluye en el elemento básico del sistema semipresidencial.

Las competencias constitucionales que configuran un papel preponderante en la actividad política del presidente, además de las ya citadas, son: el nombramiento del primer ministro, el recurso al referéndum popular, la declaración del estado de guerra, y el nombramiento de determinados cargos institucionales como los candidatos del Tribunal Constitucional, Tribunal Supremo, y el Fiscal General del Estado, o el nombramiento de los representantes de las once regiones que componen la Federación.

Sin embargo, la iniciativa legislativa es una de las competencias que pueden evidenciar el grado de implicación de un presidente en la actividad política de un sistema semipresidencial. Como es sabido, en un sistema parlamentario, aunque le corresponde al poder legislativo la aprobación de una norma con rango de ley, se le permite al gobierno la capacidad de presentar proyectos en virtud del principio de cooperación y confianza con el parlamento. En un sistema presidencial, la rigidez del principio de separación de poderes impide que el presidente pueda participar en la iniciativa legislativa, salvo en los proyectos de los presupuestos generales. Mientras que, en un sistema semipresidencial, el constituyente puede dar cabida a que dos instituciones gubernamentales puedan participar en la iniciativa legislativa: el presidente y el gabinete del primer ministro. Rusia fue pionera en establecer este tipo de posibilidad.

Las instituciones legitimadas por la Constitución rusa para presentar proyectos de leyes son, por consiguiente, la Asamblea Federal, el jefe del gobierno, el presidente de la República, y los sujetos federales en función de sus competencias (artículo 104). El presidente puede, por tanto, presentar su proyecto de ley sin necesidad de dar la orden al Consejo de Ministro. Esta doble vía fue introducida en el 
proyecto constitucional del presidente Yeltsin para el fortalecimiento de los poderes presidenciales. Con un débil sistema de partidos y la previsible incapacidad de consolidar un grupo parlamentario fuerte, Yeltsin introdujo la posibilidad de la participación legislativa del jefe de Estado ante una posible desavenencia entre presidente y primer ministro.

Es de presuponer que cuando las oficinas de la presidencia y de la jefatura del gobierno están en la misma sintonía, el recurso a la iniciativa legislativa presidencial será menor. La buena consonancia conllevaría a que la ejecución del programa presidencial se efectúe por parte del Consejo de Ministro.

Para saber cuál ha sido el grado de implicación en la iniciativa legislativa del presidente Putin, hemos elaborado un cuadro en el que se recoge el número de proyectos de ley presentados ante la Duma por la oficina presidencial durante los dos últimos años de su mandato, 2006 y 2007 (Ver cuadro 23). Podemos comprobar que la iniciativa legislativa desarrollada por el poder ejecutivo (gobierno y presidente), supuso el 47,64\% en 2006 y el 45,12\% en 2007 del total de los proyectos de ley presentados ante la Duma. Así, la iniciativa legislativa desarrollada por el presidente Putin supuso en 2006 un $9,38 \%$ del total de los proyectos presentados en la Duma por todas las entidades competentes, y un 19,6\% de los proyectos presentados en la Duma sólo por el poder ejecutivo. En 2007 hubo un incremento de la iniciativa legislativa presidencial con un $12,63 \%$ del total de los proyectos, y un $27,99 \%$ de los proyectos presentados por el poder ejecutivo.

Sería interesante determinar cuál será la iniciativa legislativa presidencial durante los primeros años del mandato de Medvedev. Si existe un grado de sintonía entre primer ministro y presidente similar al que existió durante los últimos años del mandato de Putin, se presumirá que los datos de la iniciativa legislativa presidencial serán muy similares. Sin embargo, la iniciativa legislativa no determina qué institución del gobierno dirige la actividad política. Sencillamente determina qué institución está ejecutando el programa político elaborado previamente por la voluntad de, o bien el presidente, o bien del primer ministro.

${ }^{23}$ Datos oficiales del Informe del Consejo de la Federación de 2006 y de 2007, recopilados de la página web oficial del Consejo de la Federación: www.council.gov.ru 


\subsection{La práctica política rusa y su evolución: el sistema de partidos, las mayorías parlamentarias, y el liderazgo como factor cohesionador}

La profundidad de la actividad política presidencial se puede medir a través del número de competencias asignadas en el texto constitucional, y además, de la práctica política. Es decir, del uso o desuso de las prerrogativas que el presidente ejerza en un periodo determinado. La iniciativa política del presidente en cada mandato se verá afectada por la conjunción de dos elementos: la constitución y la praxis política. A su vez, la praxis política es producto de la combinación de otros dos subelementos como son el sistema de partidos y el liderazgo ejercido por el presidente. Siguiendo esta fórmula, podremos analizar cómo ha evolucionado el grado de intervención de la institución presidencial en la vida política rusa.

La praxis semipresidencial rusa ha permanecido en constante evolución en los quince años de vigencia constitucional. Durante el mandato del presidente Yeltsin, el sistema de partidos se caracterizó por ser un sistema débil, fragmentado, y sin apenas disciplina interna dentro de sus grupos políticos. A excepción del Partido Comunista, los partidos políticos tuvieron que constituirse de forma fugaz y bajo una frágil disciplina entre la cúpula de los partidos y sus parlamentarios electos. Como resultado de esto, se configuró un parlamento multifragmentado y opuesto mayoritariamente al presidente. En la evolución del semipresidencialismo francés - como modelo paradigmático- , hemos observado que la conformación de un parlamento opuesto mayoritariamente al presidente se ha traducido en la elección de un primer ministro avalado por la Asamblea Nacional, que ha jugado un papel central en la vida política. Sin embargo, la fragmentación de la Duma y su incapacidad de avalar mayoritariamente a un primer ministro opuesto a Yeltsin, conllevó a una praxis presidencial marcada por el predominio de la actividad política presidencial. La fragmentación supuso además el recurso de Yeltsin al decreto para la ejecución de su programa. A diferencia del modelo de la Quinta República, la iniciativa política del presidente Yeltsin no se vio alterada por su enfrentamiento ante un parlamento disidente. La peculiaridad de la era de Yeltsin, en cuanto al tipo de sistema semipresidencial practicado en Rusia, se caracterizó por la coexistencia de un presidente que gobernó frente a una Duma que no fue capaz de consolidar ni una mayoría a favor del gobierno, ni una mayoría en contra de este. La mayoría 
opuesta, entre la institución parlamentaria y la ejecutiva, no tuvo por qué traducirse en cohabitación ${ }^{24}$.

La consolidación de la hegemonía del presidente de la República en la actividad política rusa se alcanzó con la construcción de un sistema de partidos sólido durante el mandato presidencial del Vladimir Putin. Para ello promovió la creación de un partido progubernamental, Rusia Unida, qué él mismo lideraría años más tarde y que obtendría la mayoría de los escaños en la Duma. La presidencia de Putin logró la instauración de facto de un sistema semipresidencial de corte president-parlamentary que siguiendo la clasificación de Shugart y Carey, se caracteriza por poseer una cierta confusión de poderes (variable constitucional) y una fuerte actividad política presidencial (práctica política).

La relación directa entre el sistema de partidos y la consolidación de una mayoría parlamentaria, adquiere una especial incidencia durante la evolución del régimen ruso. Boris Yeltsin, que fue un presidente sin partido, tenía por costumbre nombrar primeros ministros que tampoco militaban en otros partidos políticos. El gobierno, compuesto por tecnócratas sin militancia política, encontraba difícil la consolidación de una mayoría leal en la Duma que le permitiera gobernar con soltura. Para corregir esta desviación del sistema, Vladimir Putin trató de configurar una mayoría parlamentaria en base a dos ejes: la construcción de un partido político sólido, articulado, de férrea disciplina ante las decisiones de su líder, y la reforma de un sistema electoral que redujera la fragmentación parlamentaria ${ }^{25}$.

En los años noventa, el sistema electoral mixto tuvo como efecto la sobrerrepresentación de los partidos pequeños. De los 450 diputados que componían la Duma, 255 eran elegidos mediante un sistema proporcional en distritos plurinominales y listas electorales cerradas, y otros 255 eran elegidos por mayoría relativa en distritos uninominales repartidos por toda la Federación. En las elecciones de 1995, el número de diputados independientes y diputados que representaban pequeños partidos que habían ganado en algún distrito uninominal, sumaban un total de 142 escaños en la Duma. La refor-

${ }^{24}$ El apoyo mayoritario que la Duma otorgó a Primakov como Primer Ministro tras rechazar a Chernomyrdin como el favorito de Yeltsin, ni siquiera significó un gobierno de cohabitación entre Primakov y el presidente. Significó más bien que la colaboración entre ambos políticos le despertaba menos suspicacias a la Duma.

${ }^{25}$ Putin también provenía de una elite tecnócrata y no de la militancia de ningún partido político. Antes de ser nombrado primer ministro en agosto de 1999, Putin fue Director General de la FSB, antigua KGB. 
ma electoral practicada durante el mandato de Putin eliminó la elección mayoritaria en los distritos uninominales, e introdujo una barrera electoral del 7\%. El aumento en 225 escaños a repartir en una elección de representación proporcional, benefició en 2007 al partido oficialista, Rusia Unida, que obtuvo 317 diputados, y redujo la fragmentación parlamentaria a otras tres formaciones políticas: Partido Comunista (56 escaños), Partido Demócrata Liberal (40), Rusia Justa (38) ${ }^{26}$. El gobierno canalizó el apoyo popular derivado de la bonanza económica de los años 2000 y de un emergente sentimiento nacionalista, a través de Rusia Unida. Putin se consolidó como el líder del nuevo partido oficialista y situó a Rusia Unida en el centro de la actividad política.

En definitiva, la evolución de la democracia semipresidencial en Rusia, en cuanto a la consolidación de una mayoría parlamentaria y en cuanto a la forma de ejercer el poder presidencial, ha transitado en paralelo al liderazgo ejercido por cada uno de sus presidentes. Podemos por tanto clasificar la evolución del régimen en tres diferentes periodos. Un primer periodo (1991-1999) caracterizado por un liderazgo presidencial sólido, fuerte y estable. Sin embargo, la no pertenencia del presidente Yeltsin a ningún grupo político, le impidió trasladar su liderazgo a una mayoría parlamentaria. La atomización de la Duma y el recurso al decreto presidencial, hicieron que ese liderazgo «superpresidencial» - como lo llamaron algunos- se tornara cada vez más impopular durante el transcurso de su mandato.

En un segundo periodo (2000-2008), el liderazgo de Vladimir Putin facilitó el nacimiento de un partido político - Rusia Unida- que, estructurado bajo una férrea disciplina en torno al liderazgo de Putin, condujo a la solidificación de una mayoría parlamentaria en la Duma a favor del gobierno. En un tercer periodo, el nombramiento de Putin como primer ministro (2008-hoy) ha permitido un continuismo de su actividad política sin que hayan existido limitaciones formales procedentes de las competencias ejecutivas del nuevo presidente, y sin la necesidad de una reforma constitucional sustancial. Con el liderazgo en Rusia Unida y el apoyo de la mayoría parlamentaria, Putin corrige el impass que la Duma vivió durante el mandato de Yeltsin, consiguiendo que la institución parlamentaria influya en la voluntad del

${ }^{26}$ Hay que señalar que la pureza del proceso electoral se vio alterada por la denegación del Gobierno ruso a la entrada de observadores electorales de la Organización para la Seguridad y Cooperación Europea, y la detención de líderes políticos como Gari Kasparov a cuyos partidos le fueron denegada la participación en los comicios. 
presidente Medvedev de conservar la designación de Putin como primer ministro. Las propiedades del régimen semipresidencial, derivadas de su carácter ambiguo, han conllevado que la actividad política de Putin se mantenga inalterada tras su paso de la presidencia a la jefatura del gobierno. En este tercer periodo, la consolidación de un régimen semipresidencial de estilo "president-parlamentary» ha comenzado a evolucionar, con la presidencia de Dimitri Medvedev, hacia otro de estilo "premier-presidentialism».

\section{CONCLUSIONES}

La naturaleza institucional del régimen semipresidencial, constituida por una serie de elementos singulares, ha centrado el interés de políticos y académicos en la búsqueda de una nueva ingeniería constitucional. Su carácter ambiguo supone, según los intereses políticos de un determinado poder constituyente, una ventaja comparativa con respecto a otros sistemas. La capacidad de adaptación del semipresidencialismo a las variables socio-políticas de un país determinado se ha traducido en un protagonismo de este modelo en los procesos constituyentes de la tercera oleada democratizadora (1974-hoy).

Los elementos de su imprecisión se observan tanto en el plano teórico como en la práctica política. La controversia académica en la definición del concepto y la falta de consenso en la determinación de los elementos inherentes del régimen semipresidencial (a saber, la elección presidencial por sufragio popular y la sustancialidad de las competencias presidenciales), derivan en la dificultad de delimitar cuáles son los países considerados semipresidenciales y en la aplicación de un criterio subjetivo inevitable para el acotamiento de dicho listado.

Por su parte, en el plano pragmático, la ambigüedad se observa en la flexibilidad que ofrece el sistema de configurar un modelo en base a dos paradigmas. Por un lado, el constituyente puede optar por establecer un régimen con una presidencia de fuertes poderes sustanciales o, por otro lado, por un régimen con una presidencia meramente simbólica. O incluso, puede optar por una fórmula mixta dentro del eje que configura ambos paradigmas. Pero esta ambigüedad no se circunscribe únicamente al momento constituyente, sino que además, el sistema semipresidencial puede evolucionar de un modelo a otro durante su práctica política. El semipresidencialismo es susceptible a cambios en la actividad política presiden- 
cial. De esta forma, atendiendo a una serie de circunstancias determinadas, un sistema dónde el presidente es el centro de la actividad política puede girar hacia otro sistema dónde el centro de la actividad política lo constituye el primer ministro. Como se demuestra en el caso ruso, las variables que pueden influir en esa transformación son, entre otras, el sistema de partidos y el liderazgo presidencial. La imprecisión teórica y el carácter multifacético de la praxis han derivado en la consideración de que el semipresidencialismo es el sistema más adaptable en la evolución política de ciertos sistemas democráticos.

La democratización de los antiguos países del bloque comunista, tras el colapso de la Unión Soviética, nos enseña que la adopción del sistema semipresidencial es fruto de las suspicacias entre las instituciones estatales, especialmente en aquellos países con una larga tradición de gobiernos autoritarios. El deseo colectivo de alcanzar la máxima democratización de las instituciones condujo, por un lado, a la instauración de un proceso electoral para cada institución —parlamento y presidencia-, y por otro, a la búsqueda de un mecanismo de legitimidad dual que, a su vez, limitara el poder de ambas instituciones. Sin embargo, la adopción del semipresidencialismo en los países poscomunistas no se efectuó de forma homogénea. En aquellos países autoritarios (como Bulgaria o Eslovenia) que durante su transición democrática se inclinaron por constituirse bajo un semipresidencialismo de actividad presidencial simbólica (premier-presidentialism), vivieron un proceso constituyente marcado por el predominio de la institución parlamentaria, prevaleciendo un cierto consenso entre los distintos sectores sociales. Por otro lado, en aquellos países provenientes de regímenes autoritarios que optaron por constituirse bajo un semipresidencialismo de fuerte actividad presidencial (president-parlamentary), concurrió - durante el proceso constituyente- un claro predominio de la figura del presidente sobre los intereses de los grupos parlamentarios.

Pero, ¿puede un semipresidencialismo evolucionar de una tipología a otra distinta? Sí. La naturaleza ambigua del sistema lo permite y la Federación de Rusia es un buen ejemplo de ello. Rusia se constituyó en un semipresidencialismo de fuertes poderes presidenciales, dónde el centro de la actividad política ha girado en torno al presidente de la Federación. Los mandatos de los presidentes Yeltsin y Putin encauzaron el asentamiento de un sistema semipresidencial de tipo president-parlamentary. De esta forma, si analizamos la evolución del sistema ruso observaremos la relación directa de dos variables fundamentales: el liderazgo presidencial y el sistema de partidos. 
Por un lado, el mandato presidencial de Boris Yeltsin (1993-1999) se caracterizó por un liderazgo sólido favorecido por un débil sistema de partidos. Yeltsin tuvo que enfrentarse, durante todo su mandato, a un parlamento disidente pero, a diferencia de lo ocurrido en otros regímenes semipresidenciales (como en el caso de Francia), la mayoría opuesta no supuso un periodo de cohabitación. La fragmentación parlamentaria provocó la incapacidad de la Duma de imponer al presidente un primer ministro de su afinidad.

Por otro lado, el mandato de Vladimir Putin se caracterizó por la perpetuación del liderazgo presidencial de su antecesor con la introducción de ciertos cambios en el sistema, que permitieron el establecimiento de cierta estabilidad gubernamental. En el caso del sistema de partidos, los cambios introducidos mostraron una notable evolución durante el mandato del presidente Putin. Evolución que, a su vez, influyó en la praxis del régimen semipresidencial. En la corrección de los errores cometidos por su antecesor, Putin enfocó su atención en la consolidación de un parlamento favorable al Kremlin a través del establecimiento de un partido político oficialista, Rusia Unida. Con el paso de Putin desde la presidencia a la jefatura del gobierno, y con su liderazgo en Rusia Unida y, por tanto, de la mayoría parlamentaria, supone una situación insólita para el semipresidencialismo. A pesar del amplio respaldo parlamentario que recibe el presidente Medvedev, el centro de la actividad política radica en el Primer Ministro. Es de suponer, a priori, que en situaciones en las que ambas instituciones comparten una misma sintonía, como es el caso de Putin y Medvedev, se reproduciría una situación similar a la del modelo francés. Es decir, ante un presunto choque de egos entre el presidente y el primer ministro - ambos pertenecientes a la misma mayoría parlamentaria- prevalecería la voluntad del primero debido al liderazgo ejercido por éste dentro del partido. Sin embargo, el liderazgo ejercido por Vladimir Putin conlleva que la iniciativa política recaiga sobre su figura institucional.

Sólo con el paso de los años y del transcurso del mandato del actual presidente podremos concluir si la situación política en Rusia es constitutiva de un nuevo modelo de semipresidencialimo, o si, por el contrario, la situación política actual constituye un periodo político transicional más de entre las múltiples contrastes y extrañezas registradas en la historia política rusa. 


\section{ANEXOS}

Cuadro 1. Relación entre las oleadas de democratizadoras de las democracias liberales según S. Huntington y la adopción de los sistemas semipresidenciales.

\begin{tabular}{|l|c|l|}
\hline $\begin{array}{c}\text { Etapas } \\
\text { democratizadoras }\end{array}$ & $\begin{array}{c}\text { Fechas según } \\
\text { Huntington }\end{array}$ & \multicolumn{1}{c|}{$\begin{array}{c}\text { Constituciones } \\
\text { semipresidenciales }\end{array}$} \\
\hline Primera oleada & $1828-1926$ & $\begin{array}{l}\text { Weimar (1919), Finlandia (1919), } \\
\text { Austria (1920), España Segunda } \\
\text { República (1931) }\end{array}$ \\
\hline Segunda oleada & $1943-1962$ & Francia (1958), Austria (1945)... \\
\hline Tercera oleada & $1974-$ Hoy & $\begin{array}{l}\text { Portugal (1974), Rusia (1993), An- } \\
\text { tiguos regímenes comunistas... }\end{array}$ \\
\hline
\end{tabular}

Cuadro 2. Distribución de la iniciativa legislativa según las leyes aprobadas por el Asamblea Federal de la Federación Rusa en 2006 y 2007.

\begin{tabular}{|l|c|c|}
\hline Entidades con iniciativa legislativa & $\mathbf{2 0 0 6}$ & $\mathbf{2 0 0 7}$ \\
\hline El Gobierno & $106(38,26 \%)$ & $90(32,49 \%)$ \\
\hline El Presidente & $26(9,38 \%)$ & $35(12,63 \%)$ \\
\hline El Estado de la Duma & $94(33,93 \%)$ & $121(35,90 \%)$ \\
\hline $\begin{array}{l}\text { Un cuerpo legislativo de algún sujeto fede- } \\
\text { rado }\end{array}$ & $32(11,55 \%)$ & $69(20,47 \%)$ \\
\hline El Consejo de la Federación & 0 & $6(1,78 \%)$ \\
\hline La Corte Suprema de Arbitrariedad & $1(0,36 \%)$ & $3(0,89 \%)$ \\
\hline Diputados de la Duma y del Consejo Federal & $14(5,05 \%)$ & $13(3.85 \%)$ \\
\hline $\begin{array}{l}\text { Vetadas temporalmente por el Consejo Fe- } \\
\text { deral }\end{array}$ & $5(1,08 \%)$ & $6(1,78 \%)$ \\
\hline Total & $\mathbf{2 7 7 ( 1 0 0 \% )}$ & $\mathbf{3 3 7}(\mathbf{1 0 0} \%)$ \\
\hline
\end{tabular}

\section{BIBLIOGRAFÍA}

DUVERGER, M.: Instituciones políticas y derecho constitucional. Paris PUF, 1970.

ELGIE, R.: «The politics of semi-presidentialism», en Semi-presidentialism in Europe. Oxford University Press, 1999. 
HUNTINGTON, S.: La Tercera ola: la democratización de finales del siglo XX. Piados, 1998.

LEHOUCQ, F.: ¿Es el semipresidencialismo una opción viable?. Revista Política y Gobierno [México], volumen XIV, n. ${ }^{\circ}$ 2, II semestre 2007.

MALAMUD, A.: Semipresidencialismo a la portuguesa. Crisis del modelo 2004 en la cuna de la tercera ola. Boletín de la Asociación Latinoamericana de Ciencia Política, año 2004.

MARTÍNEZ, R.: El semipresidencialismo: estudio comparado. Universitat de Barcelona, 1998.

MARTÍNEZ, R. y GARRIDO, A.: Sistemas Mixtos de Tendencia Presidencial. Institut de Ciencies Politiques y Socials, Barcelona 2000.

SARTORI, G.: Ingeniería constitucional comparada. México, Fondo de Cultura económica, 1994.

SHUGART, M. S. y CAREY, J. M.: «Presidents and Assemblies». Cambridge Uni. Press 1992.

SCHLEITER, P.: «Semipresidencialismo: decisiones constitucionales y consecuencias jurídicas», en Revista Política y Gobierno [México], volumen XIV, n. ${ }^{\circ}$ 2, II semestre 2007. 